\title{
Left ventricular function outcome after coronary artery bypass grafting, King Abdullah Medical City (KAMC)- single- center experience
}

\author{
Sheeren Khaled ${ }^{1,2^{*}}$, Ehab Kasem ${ }^{2,3}$, Ahmed Fadel ${ }^{2,4}$, Yusuf alzahrani ${ }^{5}$, Khadijah Banjar $^{5}$, Wafa'a Al-Zahrani ${ }^{5}$,
} Hajar Alsulami ${ }^{5}$ and Mazad Ali Allhyani ${ }^{5}$

\begin{abstract}
Background: Coronary artery bypass grafting is known to be associated with better outcome in ischemic heart disease patients with low ejection fraction. We aim to demonstrate the effect of coronary artery bypass grafting (CABG) on left ventricle (LV) systolic function and to identify the predictors that adversely lead to postoperative poor outcome.

Result: This is a cross-sectional prospective study; we included 110 patients with left ventricular ejection fraction (LVEF) < 50\% who underwent CABG with a mean age of $56.1 \pm 12.2$ years old. Those patients were classified into two groups: group I, 76 (69\%) patients with LVEF > 35\%, and group II, 34 (31\%) patients with LVEF < 35\%. Our results as regards demographic and clinical data revealed that group II patients had a significantly higher prevalence of diabetes mellitus (DM) and Euro SCORE II compared to group I patients $(p=0.05$ and $<0.001$ respectively); otherwise, all other clinical predictors did not differ between the two studied groups. There was a significant improvement in LVEF post-surgery $(p=0.05)$ in both groups with observed no significant difference recorded for in-hospital mortality rate among patients with different groups. DM, significant diastolic dysfunction, and insertion of IABP are predictors of in-hospital mortality of the patients ( $p=0.001,0.03$ and $<0.001$, respectively)

Conclusion: We concluded that there is a significant improvement of LV systolic function after CABG and hence better survival rate. DM, significant diastolic dysfunction, and perioperative insertion of IABP are predictors of mortality after cardiac surgery. Special care should be provided to such patients to improve their outcome
\end{abstract}

Keywords: CABG, Risk predictors, Left ventricular systolic dysfunction

\section{Background}

Despite improvements in medical therapy and surgical techniques, management of patients with left ventricular (LV) dysfunction and coronary artery disease undergoing cardiac surgery is still challenging $[1,2]$. Coronary artery bypass grafting (CABG) has appeared to be superior to medical therapy alone for patients with low ejection fraction (EF), representing a significant clinical improvement and long-term

\footnotetext{
* Correspondence: sheeren.khaled@gmail.com

'Banha University, Benha, Egypt

${ }^{2}$ King Abdullah Medical City, Muzdallfa Road, Makkah, Saudi Arabia

Full list of author information is available at the end of the article
}

survival [3-7]. For these patients, CABG is associated with higher postoperative morbidity and mortality rates compared with patients with normal EF [5-9].

The studies investigating early postoperative changes have yielded conflicting results. Some have found ventricular improvement within weeks postoperatively $[10,11]$, while other studies have detected no change $[12,13]$ or a worsening of ventricular function [14].

Therefore, recognition of the predictors that increase the patients risk for a worse outcome plays a crucial role in the clinical decision-making process [15].

The aim of this study was to assess the effect of cardiac surgery on LV systolic function in patients with 
abnormal preoperative systolic function and to identify the predictors that may affect the outcome in patients undergoing CABG.

\section{Methods}

It is a cross-sectional, prospective single-center study that included 110 patients who underwent CABG at the cardiac center-King Abdullah Medical City (KAMC) during 2016 and 2017.

\section{Inclusion criteria}

Patients operated for elective isolated CABG or CABG and mitral valve (MV) repair at KAMC.

\section{Exclusion criteria}

Patients with normal left ventricular ejection fraction (LVEF), severe pulmonary hypertension, cardiogenic shock, atrial fibrillation, combined CABG with other valve intervention, and those who did not have postoperative echocardiography follow-up. Also, patients with very low $\mathrm{EF}<20 \%$ were excluded as they were rejected by our multidisciplinary team for surgery.

Demographic data (age, gender, body mass index (BMI), etc.), clinical characteristics (diabetes mellitus (DM), hypertension (HTN), renal impairment, old ischemic heart disease (IHD), type of acute coronary syndrome presentation, etc.), and surgical data (ischemic time, bypass time, postoperative intra-aortic balloon pump (IABP), and inotropes) were obtained from medical records.

\section{Surgical principals}

The surgical procedure was performed via median sternotomy with aorto-caval (single/bicaval). Cardioprotection was performed through antegrade mixed with retrograde or direct into the vein after distal anastomosis and topical hypothermia to achieve complete protection of the myocardium. The surgical procedure was done with cardioplegia every $20 \mathrm{~min}$, wean off bypass. Trans-esophageal echocardiography was done for assessment of wall motion and ventricular function after revascularization.

\section{Echocardiography}

All patients had a baseline echocardiogram before and after surgery. Subsequently, study participants were monitored repeatedly throughout the first few months after CABG, in specific regard to their LV function.

Preoperative transthoracic echocardiography (TTE) was collected as well as TTE performed after surgery. Echocardiography was performed with a vivid 7 ultrasound system. Parasternal and apical views were obtained. Ejection fraction is commonly measured by echocardiography, in which the volumes of the heart's chambers are measured during the cardiac cycle. Ejection fraction can then be obtained by dividing the volume ejected by the heart (stroke volume) by the volume of the filled heart (end-diastolic volume) [16]. Severe LV systolic dysfunction was defined in our cohort study as $\mathrm{EF}<35 \%$. Improvement in LVEF was defined as $>5 \%$ absolute increase in LVEF in comparison to the preoperative echocardiogram. Consequently, LVEF that decreased by $>5 \%$ compared to the preoperative echocardiogram was categorized as worsened. All other postoperative EF measurements within $\pm 5 \%$ of the preoperative values were categorized as unchanged [17]. Other echocardiographic parameters (diastolic function, mitral regurgitation (MR), right atrial (RA) size, right ventricular (RV) size, LV size, left atrial (LA size), right ventricular systolic function (RVSP) and RV function) all were assessed. RV function was evaluated by means of tricuspid annular plane systolic excursion (TAPSE) and tissue Doppler imaging (RV S').

\section{Statistical analysis}

Statistical analysis was performed by the use of the SPSS software package (SPSS Inc.; Chicago, IL), version 21.0. Data are presented as mean \pm SD or as median and range according to the type of distribution of each variable. Chisquare test was used to compare the existence of ventricular dysfunction pre-and postoperatively (logistic DM, HTN, smoking, dyslipidemia, CKD, MI, BNP, LVEF, LV size, TAPSE, RV size). Linear regression analysis was performed. For all analyses, a $p$ value $<0.05$ was considered significant and not significant if it is $>0.05$.

\section{Results}

Out of 264 patients undergoing coronary artery bypass grafting at the cardiac center-King Abdullah Medical City (KAMC) - in the study period, 110 had preoperative LVEF $<50 \%$. Of these, 76 (69\%) patients had LVEF > 35\% (group I), 34 (31\%) had LVEF < 35\% (group II), and all were included in the study. Baseline characteristics, comorbidities, type of operation, and intraoperative management of the study population are reported in Table 1.

Mean age was $56.1 \pm 12.2$ years, and $70 \%$ of patients were male. Mean preoperative LVEF was $29.76 \pm$ $4.868 \%$. Eighty-seven patients (79\%) underwent isolated CABG, while 23 patients (21\%) underwent combined CABG and mitral valve repair or replacement. Postoperative outcomes are reported in Table 1.

Among our patients, mortality was $5.4 \%$ and was consistent with preoperative predictions (mean Euro SCORE).

Preoperative characteristics of the two studied groups were statistically similar except for the significantly higher prevalence of DM and Euro SCORE II in group II. Operative characteristics were statistically similar between both groups (Table 2).

Early 30 -day in-hospital mortality was $5.2 \%$ in group I and $5.8 \%$ in group II, with a statistically insignificant difference. In Table 3, early mortality was observed in one 
Table 1 Demographics and clinical and operative data

\begin{tabular}{|c|c|c|}
\hline Variable & Number & Percentage \\
\hline Age & $56.1 \pm 12.2$ & - \\
\hline BMI & $27.8 \pm 5.9$ & - \\
\hline Men & 77 & 70 \\
\hline DM & 88 & 80 \\
\hline HTN & 83 & 75 \\
\hline Obesity & 52 & 47 \\
\hline CKD & 18 & 16 \\
\hline Old IHD & 83 & 75 \\
\hline STEMI presentation & 18 & 16 \\
\hline NEHA $\|/\| I$ & 83 & 75 \\
\hline Standard Euro SCORE & $6(4-8)$ & - \\
\hline High BNP & 28 & 25 \\
\hline High troponin & 98 & 89 \\
\hline LV significant systolic dysfunction & 34 & 31 \\
\hline Dilated LV diameter & 15 & 14 \\
\hline Advanced LV diastolic dysfunction & 47 & 43 \\
\hline Dilated RV dimension & 9 & 8 \\
\hline Significant MR & 31 & 28 \\
\hline Preoperative RV dysfunction & 11 & 10 \\
\hline LM disease & 15 & 14 \\
\hline Emergent surgery & 4 & 3.6 \\
\hline CABG alone & 87 & 79 \\
\hline$C A B G+M V R$ & 23 & 21 \\
\hline Perioperative IABP & 23 & 20 \\
\hline Perioperative inotropes & 6 & 5 \\
\hline Bypass time & $139.41 \pm 71.103$ & - \\
\hline Cross clamp time & $91.09 \pm 37.5$ & - \\
\hline Incomplete revascularization & 37 & 43 \\
\hline Reoperation for bleeding & 6 & 5.5 \\
\hline $\begin{array}{l}\text { Postoperative further } \\
\text { deterioration of LVEF }\end{array}$ & 36 & 33 \\
\hline Postoperative wound infection & 20 & 18 \\
\hline Postoperative AKI & 4 & 4 \\
\hline $\begin{array}{l}\text { Postoperative neurological } \\
\text { complication }\end{array}$ & 4 & 4 \\
\hline Mortality & 6 & 5.4 \\
\hline
\end{tabular}

$A K I$ acute kidney injury, $B M I$ body mass index, $B N P$ B-natriuretic peptide, $C A B G$ coronary artery bypass grafting, $C K D$ chronic kidney disease, $D M$ diabetes mellitus, Euro SCORE European System for Operative Risk Evaluation, HTN hypertension, IABP intra-aortic balloon pump, IHD ischemic heart disease, $L M$ left main, $L V$ left ventricle, $L V E F$ left ventricular ejection fraction, $M R$ mitral regurgitation, MVR mitral valve replacement, NEHA New York Heart Association,

$R V$ right ventricle, STEMI ST-Elevation Myocardial Infarction

patient (3\%) of group II and it was due to cardiogenic shock. The causes of death were cardiogenic shock (3 patients in group I and one patient in group II), multi-organ failure (one patient in group I) and respiratory insufficiency
Table 2 Comparison of demographic and clinical data between the two groups

\begin{tabular}{|c|c|c|c|}
\hline Variables & $\begin{array}{l}\text { Group I } \\
\text { (preoperative LVEF > 35), } \\
N=76(69 \%)\end{array}$ & $\begin{array}{l}\text { Group II } \\
\text { (preoperative LVEF < 35), } \\
N=34(31 \%)\end{array}$ & $p$ value \\
\hline Age $>65$ & 27 (35.5\%) & 9 (26.5\%) & 0.350 \\
\hline DM & 57 (75.0\%) & 31 (91\%) & 0.05 \\
\hline HTN & $57(75.0 \%)$ & $26(76 \%)$ & 0.117 \\
\hline Smoking & 32 (42.1\%) & $12(35.3 \%)$ & 0.500 \\
\hline Dyslipidemia & 42 (56.8\%) & 15 (45.5\%) & 0.279 \\
\hline CKD & $11(14.5 \%)$ & 7 (20.6\%) & 0.423 \\
\hline Obesity & $33(43.4 \%)$ & 19 (55.9\%) & 0.226 \\
\hline OLD IHD & $56(73.7 \%)$ & 27 (79.4\%) & 0.519 \\
\hline High BNP & 19 (55.9\%) & 9 (75.0\%) & 0.243 \\
\hline $\begin{array}{l}\text { NEHA class } \\
\|/\|\|\|\end{array}$ & 57 (75\%) & $26(76 \%)$ & 0.117 \\
\hline $\begin{array}{l}\text { Standard } \\
\text { Euro SCORE }\end{array}$ & $6(4-8)$ & $8(6-10)$ & $<0.001$ \\
\hline $\begin{array}{l}\text { High } \\
\text { TROPONIN }\end{array}$ & 64 (84.2\%) & 34 (100\%) & 0.014 \\
\hline $\begin{array}{l}\text { High Initial } \\
\text { SCR }\end{array}$ & 19 (25.0\%) & $8(23.5 \%)$ & 0.868 \\
\hline Dilated LV & 8 (10.5\%) & 7 (20.6\%) & 0.155 \\
\hline $\begin{array}{l}\text { Diastolic } \\
\text { dysfunction }\end{array}$ & $26(34.1 \%)$ & 21 (61.7\%) & 0.025 \\
\hline Dilated LA & $10(13.2 \%)$ & $5(14.7 \%)$ & 0.827 \\
\hline Dilated RA & 3 (3.9\%) & $0(0.0 \%)$ & 0.240 \\
\hline $\begin{array}{l}\text { Dilated RV } \\
\text { size }\end{array}$ & $6(8.0 \%)$ & $3(8.8 \%)$ & 0.885 \\
\hline MR & 19 (25.0\%) & $12(35.3 \%)$ & 0.267 \\
\hline TR & $5(6.6 \%)$ & $4(11.8 \%)$ & 2.688 \\
\hline $\begin{array}{l}\text { RVD } \\
\text { (reduced } \\
\text { TAPSE Pre- } \\
\text { OP) }\end{array}$ & 4 (5.3\%) & 7 (20.6\%) & 0.013 \\
\hline LM disease & 11 (14\%) & $4(12 \%)$ & 0.76 \\
\hline $\begin{array}{l}\text { Emergent } \\
\text { surgery }\end{array}$ & $2(2.6 \%)$ & $2(5.8)$ & 0.08 \\
\hline CABG alone & 59 (78\%) & $28(82 \%)$ & - \\
\hline$C A B G+M V R$ & 17 (22\%) & $6(18 \%)$ & - \\
\hline
\end{tabular}

$A K I$ acute kidney injury, $B M I$ body mass index, BNP B-natriuretic peptide, $C A B G$ coronary artery bypass grafting, $C K D$ chronic kidney disease, $D M$ diabetes mellitus, Euro SCORE European System for Operative Risk Evaluation, HTN hypertension, IABP intra-aortic balloon pump, IHD ischemic heart disease, $L A$ left atrium, $L M$ left main, $L V$ left ventricle, $L V E F$ left ventricular ejection fraction, MR mitral regurgitation, MVR mitral valve replacement, NEHA New York Heart Association, $R A$ right atrium, $R V$ right ventricle, $R V D$ right ventricular dysfunction, SCR serum creatinine, STEMI ST-Elevation Myocardial Infarction, TAPSE tricuspid annular plan systolic excursion, $T R$ tricuspid regurgitation

(one patient in group II). There were insignificant differences in postoperative complications, except the significantly higher perioperative insertion of IABP and inotropic support in group II (Table 3 and Fig. 1). 
Table 3 Operative and postoperative outcome in the studied patients

\begin{tabular}{llll}
\hline Variable & Group I & Group II & $p$ value \\
\hline Bypass time & $127.24 \pm 62.15$ & $141.05 \pm 71.31$ & 0.588 \\
Cross clamp time & $90.0 \pm 40.8$ & $92.3 \pm 37.8$ & 0.491 \\
Incomplete revascularization & $23(30 \%)$ & $14(41 \%)$ & 0.21 \\
Perioperative IABP & $12(16 \%)$ & $11(32 \%)$ & 0.009 \\
Perioperative inotropes & $1(1.3 \%)$ & $5(14 \%)$ & $<0.001$ \\
Mortality & $4(5.2 \%)$ & $2(5.8 \%)$ & 0.987 \\
Reoperation for bleeding & $5(6.5 \%)$ & $1(3 \%)$ & 0.35 \\
Postoperative further & $27(35.5 \%)$ & $9(26.5 \%)$ & 0.350 \\
deterioration of LVEF & & & \\
Postoperative wound infection & $15(20 \%)$ & $5(15 \%)$ & 0.67 \\
Postoperative AKI & $2(3 \%)$ & $2(5 \%)$ & 0.56 \\
Neurological complication & $3(4 \%)$ & $1(3 \%)$ & 0.98 \\
\hline
\end{tabular}

AKI acute kidney injury, IABP intra-aortic balloon pump, LVEF left ventricular ejection fraction

\section{Change of LV function after surgery}

Most of our patients had significant improvement of LVEF $>5 \%$ in the early postoperative period as the mean LVEF of the whole cohort increased significantly from $29.76 \pm 4.868$ before surgery to $33.53 \pm 9.655$ in the first week after surgery. Postoperative improvement in LVEF was also observed in subgroups of patients with a different type of cardiac surgery (Table 4).

\section{Predictors of adverse outcome after CABG}

$\mathrm{DM}$, significant diastolic dysfunction, and insertion of IABP all were found to be predictors of adverse outcome and mortality in the studied patients $(p=0.00$, 0.03 and $<0.001$ successively). Insertion of IABP was found as an independent predictor of mortality in different groups (Table 5).

\section{Discussion}

The identification of LVEF after CABG in patients with ischemic cardiomyopathy is considered as a crucial factor to predict the outcome. Improved function and survival following surgical revascularization have been shown in patients with LV dysfunction which is predominantly due to hibernating or stunned myocardium [17]. Our study focused on the effect of CABG on LVEF in patients with baseline impaired systolic function. In this study, a significant improvement in LV systolic function was observed with CABG. This supports the hypothesis that surgical revascularization and restoration of the blood flow to ischemic myocardium preserve already viable and functioning myocardial muscle against later infarction, recruit the hibernating myocardium, and reduce $L V$ remodeling and ischemic burden which all impact LV function recovery.

Because of the lack of routine echocardiographic examination postoperatively, few studies identified the changes in LV systolic function after CABG. Similarly, a recent study was conducted and concluded that successful results of CABG in patients with $\mathrm{EF}<50 \%$ can be achieved by careful selection of patients and management [18]. Also, another study found that a significant improvement was observed in LV systolic function in patients with preoperative systolic dysfunction [19]. Many factors contributing to the outcome of patients with baseline LV systolic dysfunction after CABG include perioperative care, severity of preoperative LV systolic dysfunction, surgical skills, complete revascularization, type of myocardial protection, cardiac anesthesia management, emergency cardiac facilities, and postoperative intensive care monitoring and management. However, Koene et al. [2] conducted a similar study and concluded that CABG is associated with worse outcome on LV systolic function [20]. A decrease in LV systolic function with CABG surgery could be

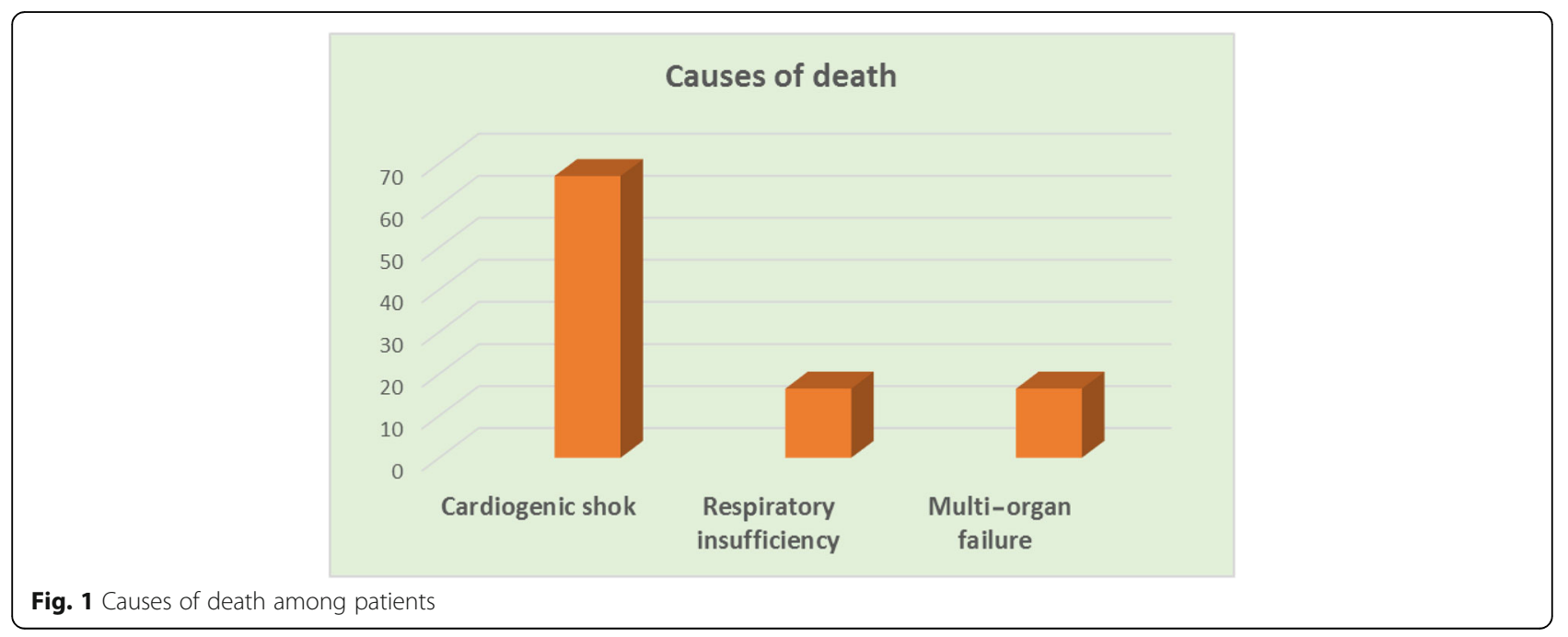


Table 4 Change in LVEF after CABG

\begin{tabular}{llll}
\hline Variable & Preoperative LVEF & Postoperative LVEF & $p$ value \\
\hline Whole cohort & $29.76 \pm 4.868$ & $33.53 \pm 9.655$ & 0.05 \\
Isolated CABG patients & $30.00 \pm 4.082$ & $35.00 \pm 10.408$ & \\
CABG + MVR patients & $27.00 \pm 4.472$ & $31.00 \pm 8.944$ & \\
\hline
\end{tabular}

$C A B G$ coronary artery bypass grafting, $L V E F$ left ventricular ejection fraction, MVR mitral valve replacement

explained by many factors: significant intraoperative global ischemia which adversely affects the LV function [21] or from myocardial stunning [22] or early postoperative graft failure [23]. In contrast also to our findings, a small study did not find a significant change in LVEF immediately post CABG [24].

Our study demonstrates that in the early mortality, 5.4\% is acceptable and in agreement with the current published data $[25,26]$. Similarly, Elassy et al. reported higher but insignificant mortality rate in patient with LVEF $<35 \%(5.6 \%$ vs $2.4 \%$ ) [27]. This is reflecting a marked improvement in the outcome of ischemic cardiomyopathy patients with CABG in highly qualified centers.

\section{Predictors of adverse outcome with CABG}

In this study, we classified our patients into two groups with and without severe LV systolic dysfunction and investigated all the predictors that could lead to poor outcome with CABG.

Type II DM was a significant predictor of adverse outcome of our patients.

Although $C A B G$ is considered the best revascularization strategy in diabetic patients, a significantly higher rate of mortality was continually observed in patients with type II DM compared to patients without type II DM [28, 29]. Reasons that have been suggested for that are more aggressive disease with advanced stage of DM in these patients,

Table 5 Univariate analysis of perioperative clinical and echocardiography risk predictors associated with in-hospital mortality in the studied patients

\begin{tabular}{lll}
\hline Variable & Mortality & Univariate $p$ value \\
\hline All patients & 6 & \\
DM & $2(33.3 \%)$ & 0.001 \\
Diastolic dysfunction II/III & $4(66.7 \%)$ & 0.03 \\
IABP & $4(66.7 \%)$ & $<0.001$ \\
Group I & 4 & \\
DM & $1(25 \%)$ & 0.001 \\
IABP & $3(75 \%)$ & $<0.001$ \\
Group II & 2 & \\
Diastolic dysfunction II/III & $1(50 \%)$ & 0.02 \\
IABP & $1(50 \%)$ & 0.001 \\
\hline
\end{tabular}

$D M$ diabetes mellitus, IABP intra-aortic balloon pump adverse effects of insulin therapy, hyperinflammatory, and hormonal hyperactivation response [30,31].

The use of intra- or postoperative IABP was a significant predictor of in-hospital mortality in all patients and when $\mathrm{EF}$ was $<50 \%$. Although the use IABP is important to support failing circulation during CABG, it is well known as a risk factor for mortality [32, 33]. It can be explained by that patients who are receiving IABP are already at high risk of increased mortality because of unstable hemodynamic status and its complications (stroke, paraplegia, limb ischemia, infection, and hemolysis) that all have an impact on mortality after CAGB $[34,35]$.

We also demonstrated advanced diastolic dysfunction as a predictor of adverse outcome and mortality in patients with LV dysfunction. Diastolic dysfunction has been reported to be an independent risk predictor of postoperative heart failure, atrial fibrillation, and cardiac death in different studies [36, 37].

Finally, a limited number of patients are included due to the nature of a single center.

Some patients also did not have echocardiography follow-up, hence excluded from our study. Follow-up echocardiography was done few months only post CABG, and thus, our results could not be correlated with longterm outcome after surgery. Like other studies evaluating adverse outcome after CABG in patients with reduced LVEF, data regarding patency of grafts were not applicable in our study. The results of this study are encouraging, and it needs corroboration in multicenter larger population with longer follow-up.

\section{Conclusion}

This study confirmed that there is a remarkable improvement of LV systolic function after coronary artery bypass grafting and that reflects the high benefit of CABG in patients with reduced EF. Diabetes mellitus, high Euro SCORE, advanced diastolic dysfunction, and insertion of IABP were significant predictors of adverse outcome. So, identification of patients with those risk predictors could provide complementary prognostic information and help to maximize the care, monitoring, and close follow-up to improve their expected poor outcome. More investigation is required for similar data in other tertiary centers to provide multicenter results and hence generalize our conclusion.
Abbreviations

AKI: Acute kidney injury; BMI: Body mass index; BNP: B-natriuretic peptide; CABG: Coronary artery bypass grafting; CKD: Chronic kidney disease; DM: Diabetes mellitus; Euro SCORE: European System for Operative Risk Evaluation; HTN: Hypertension; IABP: Intra-aortic balloon pump; IHD: Ischemic heart disease; LA: Left atrium; LM: Left main; LV: Left ventricle; LVEF: Left ventricular ejection fraction; MR: Mitral regurgitation; MVR: Mitral valve replacement; NEHA: New York Heart Association; RA: Right atrium; RV: Right ventricle; S CR: Serum creatinine; STEMI: ST-Elevation Myocardial Infarction; TAPSE: Tricuspid annular plan systolic excursion; TR: Tricuspid regurgitation 


\section{Acknowledgements}

Not applicable.

\section{Authors' contributions}

SK conceived and designed the study, participated in the sequence alignment and coordination, performed the statistical analysis, wrote the paper, helped in the data collection, and finalized the final draft of manuscript. EK participated in the sequence alignment, wrote the surgical principle part in methodology, and helped in providing the operative data and draft of the manuscript. AF participated in the sequence alignment and helped in providing most of the perioperative data and draft of manuscript. YA participated in the sequence alignment and most of the data collection and participated in the statistical analysis. KB, WA, HA, and MA participated in the data collection. All authors read and approved the final manuscript.

\section{Funding}

None.

\section{Availability of data and materials}

The data that support the findings of this study are available on reasonable request from the corresponding author but are not publicly available due to privacy.

\section{Ethics approval and consent to participate}

Our study is designed to be a part of the standard of patient care and has received approval of the ethics committee/institutional review board of the King Abdullah Medical City.

\section{Consent for publication}

Not applicable.

\section{Competing interests}

The authors declare that they have no competing interests.

\section{Author details}

${ }^{1}$ Banha University, Benha, Egypt. ${ }^{2}$ King Abdullah Medical City, Muzdallfa Road, Makkah, Saudi Arabia. ${ }^{3}$ Zagazig University, Zagazig, Egypt. ${ }^{4}$ Monofiya Neurosurgery Hospital, Shibin El Kom, Egypt. ${ }^{5}$ Umm Al-Qura University, Al Taif road, Makkah, Saudi Arabia.

\section{Received: 21 May 2019 Accepted: 21 June 2019}

\section{Published online: 05 August 2019}

\section{References}

1. Topkara, Veli K., et al. Coronary artery bypass grafting in patients with low ejection fraction. Circulation 112.9 suppl (2005): I-344.

2. Hamad MAS et al (2010) Preoperative ejection fraction as a predictor of survival after coronary artery bypass grafting: comparison with a matched general population. J Cardiothorac Surg 5.1:29

3. Alderman EL et al (1983) Results of coronary artery surgery in patients with poor left ventricular function (CASS). Circulation 68(4):785-795

4. Scott SM et al (1994) VA study of unstable angina. 10-year results show duration of surgical advantage for patients with impaired ejection fraction. Circulation 90.5 Pt 2:11120-11123

5. Zubiate P, Kay JH, Mendez AM (1977) Myocardial revascularization for the patient with drastic impairment of function of the left ventricle. J Thorac Cardiovasc Surg 73.1:84-86

6. Di Carli MF et al (1998) Long-term survival of patients with coronary artery disease and left ventricular dysfunction: implications for the role of myocardial viability assessment in management decisions. The Journal of Thoracic and Cardiovascular Surgery 116(6):997-1004

7. Passamani, Eugene, et al. A randomized trial of coronary artery bypass surgery: survival of patients with a low ejection fraction. N Engl J Med 312 26 (1985): 1665-1671.

8. John, Ranjit, et al. Long-term outcomes after cardiac transplantation: an experience based on different eras of immunosuppressive therapy. Ann Thorac Surg 72.2 (2001): 440-449.

9. Christakis GT et al (1992) Coronary artery bypass grafting in patients with poor ventricular function. Cardiovascular Surgeons of the University of Toronto. J Thorac Cardiovasc Surg 103.6:1083-1091
10. Lorusso R (2001) et al. Long-term results of coronary artery bypass grafting procedure in the presence of left ventricular dysfunction and hibernating myocardium ¿z. Eur J Cardiothorac Surg 20(5):937-948

11. Knapp M et al (2007) Myocardial contractility improvement after coronary artery by-pass grafting in a 1-year observation: the role of myocardial viability assessment. Cardiol J 14.3:246-251

12. Awan MA et al (2007) Early effects of coronary artery bypass grafting on left ventricular regional wall motion abnormalities. J Coll Physicians Surg Pak 17.1:3-7

13. Gasior $Z$ et al (2000) Long term left ventricular systolic function assessment following CABG: A prospective, randomised study. Blood versus cristalloid cardioplegia. J Cardiovasc Surg 41.5:695

14. Shepherd RL et al (1974) Deterioration of myocardial function following aorto-coronary bypass operation. Circulation 49(3):467-475

15. Heijmans JH, Maessen JG, Roekaerts PMHJ (2003) Risk stratification for adverse outcome in cardiac surgery. European journal of anaesthesiology 20(7):515-527

16. Feigenbaum, Harvey, William F. Armstrong, and Thomas Ryan. 2010 Feigenbaum's echocardiography. (c) Copyright.

17. Lee KS, Marwick TH, Cook SA, Go RT, Fix JS, James KB (1994) Prognosis of patients with left ventricular dysfunction, with and without viable myocardium after myocardial infarction: relative efficacy of medical therapy and revascularization. Circulation. 90:2687-2694

18. Kamal YA et al (2017) Predictors of adverse effects after coronary artery bypass grafting in patients with reduced left ventricular ejection fraction. Journal of the Egyptian Society of Cardio-Thoracic Surgery 25(1):20-27

19. Vakil K (2016) et al. Effect of coronary artery bypass grafting on left ventricular ejection fraction in men eligible for implantable cardioverterdefibrillator. Am J Cardiol 117(6):957-960

20. Koene RJ et al (2017) Effect of coronary artery bypass graft surgery on left ventricular systolic function. J Thorac Dis 9.2:262-270 PMC. Web. 12 Sept. 2017

21. Adabag AS et al (2007) Prognostic significance of elevated cardiac troponin I after heart surgery. The Annals of thoracic surgery 83(5):1744-1750

22. Leung JM (1993) Clinical evidence of myocardial stunning in patients undergoing CABG surgery. Journal of cardiac surgery 8(S2):220-223

23. Al Aloul, Basel, et al. Utility of nuclear stress imaging for detecting coronary artery bypass graft disease. BMC Cardiovasc Disord 12.1 (2012): 62.

24. Diller, Gerhard-Paul et al (2008) Effect of coronary artery bypass surgery on myocardial function as assessed by tissue Doppler echocardiography. Eur J CardioThorac Surg 34(5):995-999

25. Abdelgawad A, Abdelaziz A, Elshemy A, Salem E, Abdelhamid N (2012) Short term evaluation of clinical outcomes of ischaemic left ventricular dysfunction patients undergoing on pump CABG. J Egypt Soc Cardiothorac Surg 21(4):35e42

26. Abou El Ela ASA, Abdallah AK, Elgamal MA, Amer SM (2015) Coronary artery bypass surgery in patients with poor left ventricular function. J Egypt Soc Cardiothorac Surg 23(1):1e7

27. Elassy S, El-Bawab H, Abd El fatah M (2012) Early outcome of coronary artery bypass surgery in patients with poor left ventricular function. J Egypt Soc Cardiothorac Surg 20(3e4):125e31

28. Bundhun PK, Bhurtu A, Yuan J (2017) Impact of type 2 diabetes mellitus on the long-term mortality in patients who were treated by coronary artery bypass surgery: a systematic review and meta-analysis. Medicine 96(22)

29. Koshizaka M, Lopes RD, Reyes EM et al (2015) Long-term clinical and angiographic outcomes in patients with diabetes undergoing coronary artery bypass graft surgery: results from the Project of Ex-vivo Vein Graft Engineering via Transfection IV trial. Am Heart J 169:175-184

30. Dangas GD, Farkouh ME, Sleeper LA et al (2014) Long-term outcome of PCI versus CABG in insulin and non-insulin-treated diabetic patients: results from the FREEDOM trial. J Am Coll Cardiol 64:1189-1197

31. Muniyappa R, Montagnani M, Koh KK, et al (2007) Cardiovascular actions of insulin. Endocr Rev 28:463-91

32. Davoodi S, Karimi A, Ahmadi SH, Marzban M, Movahhedi N, Abbasi K et al (2008) Coronary artery bypass grafting in patients with low ejection fraction: the effect of intra-aortic balloon pump insertion on early outcome. Indian J Med Sci 62(8):314e22

33. Okonta K, Anbarasu M, Kanagarajan K (2011) Intra-aortic balloon pump in coronary artery bypass graft - factors affecting outcome. J West Afr Coll Surg 1(4):28e40 
34. Elahi MM, Chetty GK, Kirke R, Azeem T, Hartshorne R, Spyt TJ (2005) Complications related to intra-aortic balloon pump in cardiac surgery: a decade later. Eur J Vasc Endovasc Surg 29:591e4

35. Khan I, Mian HM, labal M, ljaz H, Tufail Z (2014) Prophylactic use of a preoperative intra-aortic balloon pump in patients with severe left ventricular dysfunction undergoing coronary artery bypass grafting. Egypt J Cardiothorac Anesth 8:97e100

36. Redfield MM et al (2003) Burden of systolic and diastolic ventricular dysfunction in the community: appreciating the scope of the heart failure epidemic. Jama 289(2):194-202

37. Ashes CM et al (2014) Diastolic dysfunction, cardiopulmonary bypass, and atrial fibrillation after coronary artery bypass graft surgery. $\mathrm{Br} J$ Anaesth 113(5):815-882

\section{Publisher's Note}

Springer Nature remains neutral with regard to jurisdictional claims in published maps and institutional affiliations.

\section{Submit your manuscript to a SpringerOpen ${ }^{\circ}$ journal and benefit from:}

- Convenient online submission

- Rigorous peer review

- Open access: articles freely available online

High visibility within the field

- Retaining the copyright to your article

Submit your next manuscript at $\boldsymbol{\nabla}$ springeropen.com 